In the present condition of my knowledge on this subject, I an deeply impressed with the safety and value of the high operation. For the thorough digital exploration of the bladder it is superior to perineal cystotomy.

'The same is true beyond all question in the removal of tumors.

For drainage of the bladder, whether temporary or permanent, it answers every purpose.

For removal of stone or foreign body, to my mind it is so easy, safe and satisfactory that I prefer it to the low operation. In the light of my personal experience, I do not see why suprapubic cystotomy should not supersede all other methods of cutting into the bladder.

REPORT OF A CASE OF EXTRA-UTERINE PREGNANCY. RUPTURE INTO THE PERITONEAL CAVITY AT ABOUT THE FIFTH WEEK; OPERATION THREE WEEKS AFTERWARD. RECOVERY.

Read by Tille in the Section of Obstetrics and Diseases of Homen, at Association, held at Washington, D. C., May, I89t.

BY RUFUS B. HALI, M.D., OF CINCINNATI, O

SURGEON TO THE CINCINNATI FREE HOSPITAL FOR WOMEN CLINICAL LECTCRER ON GYNECOLOGY AT THE MIAMI MEDICAL

Mrs, M., aged 30, of Winton Place, married nine years, mother of three children, the youngest 5 years old. Three years ago had an abortion and some septic trouble following, since when she has had some pelvic trouble, and been under the care of several physicians. For the past year her health was somewhat improved, yet she was not well. December 29 the menstrual flow commenced, which was the twenty-eighth day. The flow stopped January 3, and was normal in every respect. February I she commenced to menstruate, and the flow continued seven days, but it was different from former periods, inasmuch as the flow continued an hour or two or half a day, and then stopped several hours, and during the whole period she suffered more pain than ever before during menstruation. From the 7 th to the 12 th she was quite free from pain, but on the I 2 th she had cramping pain in the lower part of the abdomen, coming on after a walk of some distance. This pain was quite severe, and grew gradually worse until the $i_{5}$ th, when the family physician, Dr. R. H. Whallon, was called on account of the pain in the abdomen, which was now very severe. The doctor visited her daily for four days, at which time she appeared to be convalescent, and said she was free from severe pain. She remained quite comfortable, requiring when in conversation with her mother, she suddenly grew very pale-this was so marked that it alarmed her friends, and they requested her to lie down. Although she had no severe pain at that time, yet the whole abdomen was sore and tender. The night of the $24^{\text {th }}$ the patient got out of bed to use the conmode, and fainted twice before her husband could get her on the bed again. She was never able to get up after that date until after the operation was made. After the 24 th of February she had more or less pain all the time, with a sense of discomfort in the abdomen. March Ist to 7 th she had a simulating menstruation discharge, and discharged shreds of decidua. March 8 there was first observed an enlargement in the left side of the abdomen, as large as the closed hand, which gradually increased in size. March I I Dr. William H. Taylor was called in consultation, and diagnosed extra-uterine pregnancy, with rupture into the left broad ligament. On the I 3 th, Dr. E. W. Walker saw the case with Dr. Whallon, in Dr. Taylor's place, as the latter gentieman was unable to attend. On the I 5 th I saw the case with Drs. Whallon, Taylor and Walker. At that time there was an enlargement in the pelvis and left side of the abdomen as large as an adult head, which could be plainly outlined, extending diagonally across the abdomen from about two inches below border of the false ribs on left side, to midway between the anterior superior spine of the ilium and the pubic spine on the right. The uterus was in front of the mass, and pushed to the right side of the pelvis. The diagnosis of extra-uterine pregnancy with rupture into the folds of the broad ligament, which had been made four days previously, was believed by all present to be correct. But as the mass was increasing in size, and the patient losing strength, it was believed that an intra peritoneal rupture would probably soon occur; therefore an immediate operation was advised. After a few hours to consider it, the family decided to have it made, and it was performed on the morning of the 16 th. Present and assisting, Drs. Whallon, Taylor, Walker and Colter. When the cavity was opened, we came upon a mass in the abdomen which proved to be blood clot, as thick as jelly, and almost as black as tar. I felt first for the uterus, making certain that my hand went down upon the right side of that organ; by so doing I felt that I could better outline the parts, and as soon as the hand could be made to glide over the fundus I could at once grasp the tube near the uterus, on the side of rupture, and thus control hæmorrhage. By this method, I did not lose any time in definitely locating the parts. I first attempted to bring the tube into the incision, but the decidua became detached, and with some blood clot was removed. I at once secured the tube which formed the sac and tied no medicine to relieve pain, and on the $22 \mathrm{~d}$ she it off. I now turned my attention to cleansing took a drive with some friends. On the $23 \mathrm{~d}$, the abdominal cavity from blood clot, of which 
there was an incredible amount, estimated to be about $4 \frac{1}{2}$ pints. After thorougbly irrigating the cavity and placing a drainage-tube, the cavity was closed. The patient recovered without incident, and was able to sit up on the twentieth day after the operation. It is very difficult to say whether the rupture occurred on the $15^{\text {th }}$ or the $2 t^{\text {th }}$ of February, but it is a matter of scientific and practical interest to settle as near as possible; this, however, can only be approximate in this case. We are certain that it occurred as early as the $24^{\mathrm{th}}$, if not on the $15^{\mathrm{th}}$, and I am very strongly inclined to the opinion that it occurred at the time of her first severe pain, on the $15^{\text {th. }}$.

It was probably the loss of blood that caused her to faint on the 24th. This belief is strengthened by the fact that on March 8 the abdominal enlargement was first observed, which would quite agree with the theory that the bleeding went slow$1 y$ on during the interval, and the fluid portion being absorbed, leaving the blood clot, forming the enlargement. I recorded the case because these cases are always interesting, and to emphasize and illustrate a few facts in connection with this case which are of vast practical importance to the general practitioner and specialist alike. In this case there was not a single symptom or sign to lead one to believe that there was an intra-peritoneal rupture, yet the rupture was free under the peritoneal cavity, and not into the broad ligament, as we all believed before the operation. The pelvic floor was displaced downward, and the tumor was rounded and felt.firm and fixed, as we would expect to find in a case of rupture into the broad ligament. This deceptive condition can now be explained in the following manner: The rupture occurred early at the end of the fourth or fifth week of gestation, near the middle of the tube, on its free border. This, at first, was probably quite small, and bled slowly, the more fluid portion of the blood being absorbed, leaving the blood clot, which the omentum and intestine became adherent to, closing off the greater portion of the abdominal cavity from contamination. As the bleeding continued, the intestine and omentum were crowded away from the left iliac fossa, but at the same time keeping the blood clot confined in that locality, thus making the apparent tumor. Adhesions of several weeks' duration were quite firm, and thus we can account for the depression of the pelvic floor simulating a rupture into the broad ligaments.

If we had waited for the absorption of that amount of blood clot, with the bleeding still going on, we would have lost our patient. The case demonstrates the difficulty attending a correct diagnosis as to intra- and extra-peritoneal rupture in extra-uterine pregnancy, as well as the danger of attempting the same-thus encouraging delay. We had in this case the very signs which are believed to be characteristic of rupture into the folds of the broad ligament, when it was really a rupture free into the peritoneal cavity, as the specimens plainly show. With these facts before us, after we have made our diagnosis of extra-uterine pregnancy, are we to stand idly by and wait until we are certain the sac has ruptured into the peritoneal cavity, in any given case, before we recommend an operation? This is a very important question, and one that is by no means settled in the professional mind, but the careful study and report of these cases will soon settle this difficult problem. I now believe, if the case comes under observation before the fourth month, it is our duty to give the patient the best chance for her life; and that is an abdominal section, and that without delay. I here present the specimens in these three bottles. In the first one you will see the left tube, dilated into a sac the size of a small orange, with a rupture in the free border. In the second bottle you will find the decidua and blood clot. This clot, with the decidua and fœtus, were in the tube at the time of the operation, and came away in my hand when I first attempted to bring the tube into the incision. The foetus, which is in the third bottle, was afterward found in the blood clot by Dr. Taylor, and as you see, is less than one inch in length.

\section{RUPTURED UTERUS. OPERATION AND AMPUTATION OF A SECTION OF} INTESTINE. A UNIQUE CASE.

BY H. WARDNER, M.D., of CHICAGO, ILL.

Trusting the following report may be of interest, I send it to THE JournaL, in the hope that if there is a similar case on record, or having occurred in the practice of any physician, it may come to light. So far, I have not been able to find one in medical literature, or in the experience of physicians with whom I have conversed on the subject.

On Sunday, August I I, I 889, I was requested by my friend Dr. Dodds, of Anna, I1l., to visit with him a patient in a neighboring village, a young married woman, who seemed to be suffering from a delayed miscarriage, about which there was something unusual.

From the doctor, the patient and her husband, who was also a physician, I obtained in substance the following history of the case: On Wednesday evening, the 7 th, she was at Anna, where, in running to catch the train just starting from the depot, she jumped and partly fell in getting aboard the car. She "felt something give away," and an uneasy feeling followed, coupled with more or less pain. After reaching her home, she spent the time up to nine o'clock playing croquet, although the bad feelings con- 